\title{
The Association between Physical Frailty and Psycho-Social Health in Determining Geriatric Health-Related Quality of Life in Rural India
}

Sayani Das ( $\nabla$ das.sayani6@gmail.com )

Ministry of Social Justice and Empowerment https://orcid.org/0000-0003-2663-0775

\section{Susmita Mukhopadhyay}

Indian Statistical Institute, Kolkata

Barun Mukhopadhyay

Indian Statistical Institute, Kolkata

\section{Research Article}

Keywords: Community-dwelling, Elderly health, Gerontology, HRQoL, Rural India

Posted Date: September 28th, 2021

DOI: https://doi.org/10.21203/rs.3.rs-864050/v1

License: (c) (i) This work is licensed under a Creative Commons Attribution 4.0 International License.

Read Full License 


\section{Abstract}

The association of physical frailty and psycho-social health is well established. However, it appears no study on the interaction of these conditions in determining the Health-related Quality of Life (HRQoL) has yet been attempted in India. Hence, present study aims to investigate the interaction effects of physical frailty and psycho-social health in determining the HRQoL. A cross-sectional survey was conducted on 500 community-dwelling rural elderly participants from West Bengal, India. The modified Fried's Frailty instrument was assessed physical frailty status. Psycho-social characteristics investigated were depression, anxiety and stress using the 21-item DASS instrument, loneliness using the UCLA Loneliness instrument, and cognitive function using the Mini-Mental State Examination instrument. HRQoL was assessed by the 36-items Short Form health survey questionnaire. Overall prevalence of frail, pre-frail and non-frail was $26.2 \%, 60.2 \%$, and $13.6 \%$, respectively. One-way ANOVA highlighted that mean scores of psycho-social traits are significantly differed among different physical frailty status groups $(p<0.01)$. All the elderly participants were clustered with their psycho-social characteristics instrument scores as clustering variables using Hierarchical Cluster Analysis to understand psycho-social health of the participants. Two-way ANCOVA showed significant interaction of physical frailty status (frail, pre-frail and non-frail) and empirically occurring clusters of psycho-social health (low, moderate and good) in determining the overall HRQoL $[F(8,491)=8.904, p<0.01]$. Thus, our findings suggest that consideration of physical frailty and psycho-social health status will be a prudent approach for a better diagnosis of HRQoL and challenges related to the same.

\section{Introduction}

India, the world's second-most populous country, had an elderly population of 12.1 million in 1901 and that increased to approximately 104 million in the Census year, 2011. The number of elderly people in India is projected to reach 140 million by 2021 (MoS\&PI, 2011). Life expectancy at birth in 2000 was 62.1 years and the healthy life expectancy at birth was 52.9 years in India; while in 2019, the average life expectancy of birth increased to 70.8 years and the healthy life expectancy at birth 60.3 years (WHO, 2020). This implies that life expectancy is increasing but it is not necessary that there should be an equal rise in healthy and work capable life. Thus, there is growing need to improve understanding of the determinants of healthy quality of life.

Many serious public health problems are related to the later years of life, and one of the most challenging issues for gerontologists is the 'frailty syndrome'. Fried et al. (2001) hypothesized to have an underlying physical basis of this syndrome, and they defined it as the presence of three or more out of five physiological deficits, e.g. muscle weakness, low gait speed, unintentional weight loss, exhaustion, and low physical activity. This complex syndrome is highly prevalent in the older adults throughout the world, including India (Biritwum et al., 2016). It is noted that research on several dimensions of physical frailty in India is still in its infancy. 
Epidemiological evidences suggested that the physical frailty and poor psycho-social health is significantly associated (Mhaolain et al., 2012; Kelaiditi et al., 2013; Herrera-Badilla et al., 2015; Lohman et al., 2016; Kashikar \& Nagarkar 2016; Ma et al., 2019), and the combination of both may worsen an individual's vulnerability and influence the subsequent decline in healthy quality of life (Gobbens \& van Assen, 2014). In India, the elderly people are facing financial hardship with material exploitation, assets grabbing and humiliation, all of which impacting their health seeking behavior and psychological torment (Dey et al., 2020). But it appears that no study on the association of physical frailty with psycho-social health in determining the health-related quality of life has yet been attempted in India. The present study is set out to fill this gap.

The hierarchy of human needs theory (Maslow, 1999) guided the study. This theory is appropriate for this study because it incorporates process of meeting needs holistically, not merely their physical ability. We hypothesized that the interaction effect of physical frailty and psycho-social health can potentially affects the quality of life among the elderly population. Data available on India's urban and rural elderly population (WHO's SAGE data 2007-08) illustrated that the state of West Bengal, has the highest percentage of people with low quality of life (QoL) than the other Indian States (Chaudhary \& Arokiasamy, 2019). Therefore, we find it necessary to understand the association of physical frailty with psycho-social health, and its interaction effects in determining the QoL among the community-dwelling rural elderly population of West Bengal, India.

\section{Methodology}

\section{Study area}

The present study was conducted in Pancharul Gram Panchayat (local level unit for the governance of rural areas) under Udaynarayanpur Block, located in the district of Howrah of the State of West Bengal in India. Howrah is the nearest town to Pancharul, which is approximately $51 \mathrm{~km}$ away. The nearest railway station of Pancharul is about $23 \mathrm{~km}$. away (Amta Railway Station). The total geographical area of Pancharul is 410.02 hectares, and the total population of this area is 6,678 persons. Out of the total population, 4,714 people in Pancharul Village are literate. There is only one community health centre, but exclusive geriatric outpatient services are not available in this centre (MHA, 2011).

This study is the part of a large project that examines the effect of a rural geriatric welfare programme on geriatric quality of life. This particular community was purposely selected because a geriatric welfare programme is ongoing in this block, and it also possesses multi-ethnic, single language-speaking (Bengali, the predominant local language of West Bengal) agricultural group, which is a general feature of rural West Bengal.

\section{Sampling}

This study follows a population-based cross-sectional design. No statistical sampling procedures have been adopted for the selection of study participants. Household listing was made from the panchayat 
electoral rolls (Voter list). Based on this selection frame all the eligible individuals (aged 60 years and above) of Pancharul gram panchayat were approached for participation. The sampling frame enumerated a total of 623 elderly individuals inhabiting a cluster of villages of Pancharul gram panchayat. Out of 623 elderly individuals, 500 participants (226 males and 274 females) completed the face-to-face interview by a single researcher and were included in this study between October 2018 and January 2020. All the questionnaires were administered in Bengali, the mother tongue of study participants. The inclusion criteria for the participants were willing elderly individuals providing consent to participate, and living in the selected villages for more than ten years. Those aged below 60 years, on cross-checking of age, and elderly people with disabilities, both physical and mental, were excluded.

\section{Instruments}

Socio-demographic characteristics: First of all, Socio-demographic data were collected on age, sex, marital status, living arrangement, occupational status, educational status and socio-economic status. Marital status was categorized as unmarried, married (living with spouse) and widowed. Living arrangement was grouped into three categories, living alone, nuclear family (a social unit of two parents and their unmarried dependent children) and joint family (a family living together with all family members irrespective of marital status up to 2 nd generation). The occupational status was categorized as working and non-working. Educational status was grouped into two categories, less than primary education (school education up to class four), and primary education and above. Udai Pareek scale (revised) was used to collect socio-economic status information (Wani, 2019). This scale is well used to understand the socio-economic status of a family in rural India. In the present study, the reliability of the socio-economic status scale was $\mathrm{a}=0.78$.

Physical frailty assessment: Physical frailty was evaluated using the modified Fried Physical Frailty Scale (Fried et al., 2001). This screening tool consists of five physiological deficits.

1. Low weight: Score based on the lowest quintile of Body Mass Index [defined as the body weight $(\mathrm{kg}$.) divided by the square of the height $(\mathrm{m}$.)] for both sexes. Standing height was measured using Anthropometer rod (with the least count of $0.1 \mathrm{~cm}$ ) and body weight using digital weighing machine (OMRON Model HBF-514).

2. Slow walking speed: Score in the bottom quintile of observed values for the 4-meters times walk at a usual walking pace [adjusted for sex and height (median)].

3. Reduced muscle strength: Score in the bottom quintile of observed values for handgrip strength [adjusted for sex and Body Mass Index]. Handgrip strength in kilograms was measured three times, using a Jamar Hand Dynamometer. The measurement was taken on the dominant hand.

4. Exhaustion: Individuals were asked whether they have had enough energy for their daily activities. Those who responded 'a little' or 'not at all', were denoted as exhausted.

5. Low energy expenditure: Individuals' total physical activity levels were calculated by the Global Physical Activity Questionnaire (GPAQ) (Mumu et al., 2017). Score based on the low level of physical activity according to the cut-off of GPAQ. This scale considers an individual as 'frail' if they display 
any three or more out of these five deficits, an individual as 'pre-frail' if they display any one or two out of these five deficits, and others are categorized as 'non-frail'.

\section{Psycho-social characteristics}

Depression, anxiety and stress was measured based on DASS-21 (Lovibond \& Lovibond, 1995). It is a set of three self-report subscales, seven items per subscale, to access the emotional states of depression, anxiety and stress level. In the present study, the DASS reliability was $a=0.86$ for depression, $a=0.75$ for anxiety and $a=0.77$ for stress. The UCLA Loneliness Scale (Russell et al., 1980) was used to measure one's subjective feelings of loneliness. The total UCLA-loneliness score is 20 items, which exhibited high internal consistency in the present sample $(a=0.92)$. The Bangla Adaptation of the Mini-mental State Examination (BAMSE) (Kabir et al., 2020) scale (30-point questionnaire) was used to assess the cognitive function. Cronbach's a value in the present study for cognitive function (BAMSE) was 0.70 . Higher scores of the DASS-21 and the UCLA Loneliness scale indicate a greater degree of depression, anxiety, stress and loneliness. Lower scores of the BAMSE scale indicate a lower degree of cognitive function.

Heath-related Quality of life: The Bengali Short Form-36 (SF-36) health survey questionnaire was used to measure Health-Related Quality of Life (HRQoL) (Feroz et al., 2012). This scale consists of eight subscales: physical functioning, role limitations due to physical health, role limitations due to emotional problems, energy/fatigue, emotional well-being, social functioning, body pain and general health. Aggregate scores are compiled as a percentage of the total point yielding overall score. The higher the overall score, the less disability, i.e., a score of zero is equivalent to a maximum disability, and a score of 100 is equivalent to no disability. Cronbach's a of 0.97 was obtained in the present study.

\section{Data analysis}

Descriptive analysis was performed to report the proportions for the categorical variables of sociodemographic characteristics. Multiple linear regressions were performed to find out the association of HRQoL with socio-demographic characteristics. Analysis of Variance (ANOVA) was used to compare the difference in psycho-social characteristics among the frail, pre-frail and non-frail status groups. Cluster analysis was used to identify homogeneous groups of psycho-social characteristics. The hierarchical cluster analysis with Ward's method, applying squared Euclidian distance followed by k-means clustering was conducted to make clusters of psycho-social health based on attaining the extent of the selected psycho-social characteristics instrument scores. One-way ANOVA was also conducted to understand the significant differences across the means of the cluster groups of psycho-social health. Finally, adjusting baseline covariates, a two-way Analysis of Covariance (ANCOVA) was used to identify the association of HRQoL with physical frailty and psycho-social health, respectively. It also highlights the interaction effects of physical frailty and psycho-social health in determining the health-related quality of life. A p value of $<0.05$ was considered statistically significant. Statistical analysis was performed using SPSS (Windows version 20; IBM Corp, Armonk [NY], US).

\section{Results}




\section{Socio-demographic characteristics}

Table 1 presents the socio-demographic characteristics of elderly study participants. Out of 500 elderly study participants, 261 (52.2\%) of the participants are aged 70 years and above. Most of the elderly in this study were female (54.8\%) and married (55.2\%). There was no any unmarried elderly participant. A large number of participants (73.4\%) were living in a joint family. $63.6 \%$ of the study participants' experienced less than primary education, and $65 \%$ belonging to non-working category. $79.2 \%$ of elderly participants belonged to the lower-middle socio-economic status. 
Table 1

Socio-demographic characteristics of the study population

\begin{tabular}{|lll|}
\hline Characteristics & \multicolumn{2}{l|}{ Total } \\
& \multicolumn{2}{l|}{$\mathbf{N = 5 0 0}$} \\
\cline { 2 - 3 } & N & $\%$ \\
\hline Age (years) & & \\
\hline$\geq 70$ & 261 & 52.2 \\
\hline $60-69$ & 239 & 47.8 \\
\hline Sex & & \\
\hline Female & 274 & 54.8 \\
\hline Male & 226 & 45.2 \\
\hline Marital status & & \\
\hline Widowed & 224 & 44.8 \\
\hline Married & 276 & 55.2 \\
\hline Living arrangement & & \\
\hline Living alone & 43 & 8.6 \\
\hline Nuclear family & 90 & 18.0 \\
\hline Joint family & 367 & 73.4 \\
\hline Educational status & & \\
\hline$<$ Primary & 318 & 63.6 \\
\hline$\geq$ Primary & 182 & 36.4 \\
\hline Occupational status & & \\
\hline Non-working & 325 & 65.0 \\
\hline Working & 175 & 35.0 \\
\hline Socio-economic status & & \\
\hline Lower class & 43 & 8.6 \\
\hline Lower middle class & 396 & 79.2 \\
\hline Middle Class & & 12.2 \\
\hline
\end{tabular}




\section{Overall HRQoL and its association with socio-demographic characteristics}

Multiple linear regression analysis evaluated the influential factors related to overall HRQoL (total SF-36), as illustrated in Table 2. The findings demonstrated that elderly participants aged 60-69 years experienced an overall good HRQoL $(p<0.01)$, suggesting that lower age was associated with better HRQoL. This study also highlighted that those elderly participants who are presently working, have good HRQoL. Nevertheless, the other socio-demographic variables (sex, marital status, living arrangement, educational status and socio-economic status) do not showany significant association with overall HRQoL. 
Table 2

Association of overall HRQoL with socio-demographic characteristics

\begin{tabular}{|lc|}
\hline & \multicolumn{1}{|c|}{ Overall HRQoL (Total SF-36) } \\
\hline Age $(60-69 />70-y e a r s)$ & \\
\hline Non-standardized B & -14.0 \\
\hline Std. Error & 1.9 \\
\hline Sig. & $<0.01$ \\
\hline Sex (Male/ Female) & \\
\hline Non-standardized B & 4.8 \\
\hline Std. Error & 2.5 \\
\hline Sig. & 0.06 \\
\hline Marital status (Married/ Widow) \\
\hline Non-standardized B & -0.9 \\
\hline Std. Error & 2.2 \\
\hline Sig. & 0.69 \\
\hline Living arrangement (Joint family/ Nuclear family/ Living alone) \\
\hline Non-standardized B & 0.3 \\
\hline Std. Error & 1.4 \\
\hline Sig. & 0.81 \\
\hline Educational status $(\geq$ Primary/ $<$ Primary) \\
\hline Non-standardized B & -3.3 \\
\hline Std. Error & 2.2 \\
\hline Sig. & 0.13 \\
\hline Occupationalstatus (Working/Non-working) \\
\hline Non-standardized B & -15.1 \\
\hline Std. Error & 2.2 \\
\hline Sig. & \\
\hline Socio-economic status (Middle class/ Lower middle class/ Lower class) \\
\hline Non-standardized B & -3.7 \\
\hline
\end{tabular}




\begin{tabular}{|ll|}
\hline & Overall HRQoL (Total SF-36) \\
\hline Std. Error & 2.3 \\
\hline Sig. & 0.11 \\
\hline $\mathbf{R}^{2}$ & 0.264 \\
\hline
\end{tabular}

\section{Prevalence of physical frailty and its association with psycho-social traits}

The scores of psycho-social characteristics among different physical frailty status groups are demonstrated in Table 3. According to Fried's criteria, $13.6 \%(n=68)$ of participants were categorized as non-frail, $60.2 \%(n=301)$ as pre-frail, and $26.2 \%(n=131)$ as frail. One-way ANOVA result revealed that the mean of all psycho-social trait scores significantly differed among different physical frailty status groups (all $p<0.01$ ). Tukey post-hoc test revealed that the frail elders reported significantly lower scores than both pre-frail and non-frail ones (all $p<0.01$ ) for all psycho-social characteristics. The mean scores of psycho-social characteristics are significantly different between pre-frail and non-frail (pre-frail vs nonfrail, $p<0.01$ ) elderly study participants for stress, anxiety, depression and loneliness.

\begin{tabular}{|c|c|c|c|c|c|c|c|c|c|}
\hline \multirow{3}{*}{ Psycho-social traits } & \multirow{3}{*}{ Mean } & \multirow{3}{*}{ SE } & \multicolumn{7}{|c|}{ Physical frailty } \\
\hline & & & \multicolumn{2}{|c|}{$\begin{array}{l}\text { Frail } \\
\mathrm{n}=131(26.2 \%)\end{array}$} & \multicolumn{2}{|c|}{$\begin{array}{l}\text { Pre-Frail } \\
n=301(60.2 \%)\end{array}$} & \multicolumn{2}{|c|}{$\begin{array}{l}\text { Non-Frail } \\
n=68(13.6 \%)\end{array}$} & \multirow{2}{*}{$p$-value } \\
\hline & & & mean & SE & mean & SE & mean & SE & \\
\hline Stress & 8.7 & 0.3 & 11.2 & 0.5 & $8.3^{*}$ & 0.3 & $6.1^{\text {怄 }}$ & 0.7 & $<0.01$ \\
\hline Anxiety & 6.6 & 0.3 & 10.0 & 0.5 & $5.8^{*}$ & 0.3 & $3.3^{\star \star \rrbracket}$ & 0.5 & $<0.01$ \\
\hline Depression & 22.3 & 0.4 & 28.9 & 0.6 & $21.0^{\star}$ & 0.5 & $14.9^{\star \star \rrbracket}$ & 0.9 & $<0.01$ \\
\hline Loneliness & 44.4 & 0.5 & 50.9 & 0.8 & $43.2^{*}$ & 0.6 & $37.0^{\star \star \mathbb{Z}}$ & 1.1 & $<0.01$ \\
\hline Cognitive function & 23.8 & 0.2 & 22.4 & 0.3 & $24.2^{*}$ & 0.2 & $24.9^{*}$ & 0.5 & $<0.01$ \\
\hline \multicolumn{10}{|l|}{ SE, Standard Error } \\
\hline \multicolumn{10}{|c|}{ \#values based on one-way ANOVA } \\
\hline \multicolumn{10}{|c|}{${ }^{*}$ The mean difference is significant at 0.01 level reference to frail } \\
\hline \multicolumn{10}{|c|}{${ }^{\mathbb{}}$ The mean difference is significant at 0.01 level reference to pre-frail } \\
\hline
\end{tabular}




\section{Empirically occurring clusters of psycho-social health}

The total number of elderly participants $(N=500)$ were clustered with their psycho-social characteristics instrument scores as the clustering variables using Hierarchical Cluster Analysis with Ward's Method on squared Euclidian distances. A three-cluster solution provided significant clearest differentiation among groups $(p<0.01)$. Table 4 includes descriptive statistics for the three-cluster analysis-derived groups of psycho-social health on the basis of psycho-social characteristics instrument scores. The first cluster $(\mathrm{n}=$ 125) scored high on stress, anxiety, depression, loneliness, and low on cognitive function; thus, this group was labelled as 'low psycho-social health'. The second cluster $(n=180)$ were included medium psychosocial instrument scores compared to the other two cluster groups, and assigned as 'moderate psychosocial health'. In contrast, the third cluster $(n=195)$ scored low on all four psycho-social characteristics (stress, anxiety, depression, loneliness) and high on cognitive function score, and therefore were assigned the name 'good psycho-social health'.

Table 4

Descriptive Statistics (Means and Standard Deviations) of Three Cluster Analysis-Derived Groups of psycho-social health on Psycho-social trait Measures

\begin{tabular}{|lllll|}
\hline Psycho-social characteristics & \multicolumn{2}{l}{ Psycho-social health } & One-way ANOVA \\
\cline { 2 - 5 } & Low & Moderate & Good & p-value \\
& $(\mathbf{n = 1 2 5 , 2 5 \% )}$ & $(\mathbf{n = 1 8 0 , 3 6 \% )}$ & $(\mathbf{n = 1 9 5 , 3 9 \% )}$ & \\
\hline Stress & $14.48(0.6)$ & $9.01(0.3)$ & $4.90(0.3)$ & $<0.01$ \\
\hline Anxiety & $12.74(0.5)$ & $6.34(0.3)$ & $2.85(0.2)$ & $<0.01$ \\
\hline Depression & $32.30(0.4)$ & $23.72(0.4)$ & $14.44(0.4)$ & $<0.01$ \\
\hline Loneliness & $57.25(0.4)$ & $47.54(0.5)$ & $33.18(0.4)$ & $<0.01$ \\
\hline Cognitive function & $22.08(0.3)$ & $23.37(0.2)$ & $25.28(0.2)$ & $<0.01$ \\
\hline
\end{tabular}

\section{Interaction effects of physical frailty and psycho-social health in determining overall HRQoL}

The two-way ANCOVA was conducted to determine the association between physical frailty status (frail, pre-frail and non-frail) and empirically occurring clusters of psycho-social health (low, moderate and good) in determining the overall health-related quality of life, after adjusting age and occupational status (Table 5). The result showed a significant interaction effect of physical frailty and psycho-social health on overall HRQoL $[F(8,491)=8.904, P<0.01]$ (Table 5). Specifically, a significant simple main effect of physical frailty was found on overall HRQoL $(p<0.01)$. Furthermore, the sidak post-hoc test showed that 
overall HRQoL in frail elderly was lower than pre-frail and non-frail elderly (all $p<0.01$ ). A significant difference in overall HRQoL was also found between pre-frail and non-frail $(p=0.018)$. Similarly, psychosocial health also had a significant main effect on overall HRQoL, $(p<0.01)$. The sidak post-hoc test revealed that HRQoL was better among those who have moderate $(p=0.003)$ and good $(p<0.01)$ psychosocial health compared to those with low psycho-social health. There were significant differences between elderly study participants with moderate and good psycho-social health levels $(p<0.01)$ in terms of overall HRQoL.

Table 5

Association of physical frailty and psycho-social health in determining overall HRQoL

\begin{tabular}{|c|c|c|c|}
\hline Physical Frailty & Psycho-social Health & Overall HRQoL & Sig. \\
\hline \multirow[t]{3}{*}{ Frail } & Low & $28.12 \pm 2.0$ & $<0.01$ \\
\hline & Moderate§ & $33.36 \pm 2.3$ & \\
\hline & Good $\S^{\bigotimes}$ & $51.99 \pm 4.2$ & \\
\hline \multirow[t]{3}{*}{ Pre-frail $^{\star}$} & Low & $37.70 \pm 2.2$ & \\
\hline & Moderate $\S$ & $50.42 \pm 1.4$ & \\
\hline & Good $\S^{\rrbracket}$ & $63.15 \pm 1.4$ & \\
\hline \multirow[t]{3}{*}{ Non-frail ${ }^{\star \#}$} & Low & $47.76 \pm 7.8$ & \\
\hline & Moderate ${ }^{\S}$ & $61.32 \pm 4.0$ & \\
\hline & Good $\S^{\rrbracket}$ & $68.85 \pm 2.3$ & \\
\hline \multicolumn{4}{|c|}{ Age and present occupational working status are used as covariates. } \\
\hline \multicolumn{4}{|c|}{ Data are the mean \pm standard error. } \\
\hline \multicolumn{4}{|c|}{ A lower score of overall HRQoL indicates the severe health-related quality of life } \\
\hline \multicolumn{4}{|c|}{${ }^{*} p<0.01$ versus physically frail participants within the same psycho-social group } \\
\hline \multicolumn{4}{|c|}{$\#_{p}<0.01$ versus physically pre-frail participants within the same psycho-social group } \\
\hline \multicolumn{4}{|c|}{$\S_{p}<0.01$ versus low psycho-social health within the physical frailty group } \\
\hline \multicolumn{4}{|c|}{${ }^{\mathbb{Q}}<0.01$ versus moderate psycho-social health within the physical frailty group } \\
\hline
\end{tabular}

\section{Discussion}


The present study highlights that physical frailty status is significantly associated with psycho-social health. We found that physical frailty can predict an increased level of stress, anxiety, depression, and loneliness while decreasing cognitive function. Mhaolain et al. (2014) also emphasized the higher likelihood of depression and anxiety in later life among the frail elderly population, and they identified frailty as a marker of deteriorating mental health. Health and Retirement Study (2010) from the U.S. households comprehensively explained a positive correlation between depression and frailty. This study highlights that understanding of psycho-social traits of frail is very useful for predicting declining health and disability in later life (Lohman et al., 2016). The study among the Mexican city's community-dwelling elderly population (Herrera-Badilla et al., 2015) found that loneliness was independently associated with frailty. In China, a study was conducted to understand the cognitive function among the pre-frail and frail community-dwelling population, and they found that frailty was significantly associated with cognitive function (Ma et al., 2019). An international consensus group comprising investigators from the International Academy of Nutrition and Aging (IANA) and the International Association of Gerontology and Geriatrics (IAGG) established a definition for 'cognitive frailty' in elderly population to increase the awareness about the fact, that many elderly populations with physical frailty are also prone to the problems related to cognitive function (Kelaiditi et al., 2013). However, the relationships of physical frailty with different psycho-social characteristics are overlapping and multidimensional. One of the major adverse outcomes of the interrelationship between physical frailty and psycho-social factors may impinge on a low quality of life. But there is a dearth of information regarding the interaction effects of physical frailty and psycho-social health in determining the health-related quality of life among the elderly population. Hence, present study examines the same, and the result reveals that the association of frail and low psycho-social health is an essential predictor of adverse HRQoL. Our findings suggest that consideration of physical frailty and psycho-social health status will be a prudent approach for a better diagnosis of HRQoL and challenges related to the same.

\section{Conclusion}

This is an original research study conducted on the rural community-dwelling elderly population, and it includes physical frailty and all the necessary psycho-social characteristics that are broadly considered the primary factors of HRQoL. Few studies include community-dwelling rural elderly to study physical frailty, as most of India's studies are based on hospitalized patients, staying in-home care, or urban community-dwelling population. Furthermore, the comprehensive study on the interaction of physical frailty and psycho-social health is also not available among the community-dwelling rural elders. To best of our knowledge, this is the first study reporting the association between physical frailty and psychosocial health in determining geriatric HRQoL in rural India.

\section{Declarations}

Funding: The authors disclosed receipt of financial support from India's University Grants Commission [Award No. F.15-9(JULY 2016).2016(NET)] for this research. 
Conflict of interest: The authors declared no potential conflicts of interest for the research, authorship, and/or publication of this article.

Availability of data and material: Not applicable.

Code availability: Not applicable.

Ethical approval: Present study was approved by the Review Committee for the protection of Research Risks to Humans, Indian Statistical Institute, Kolkata (ISI-IEC/2018/10/02).

Consent to participate: Participants were explained before the commencement of the data collection about the objectives of the study and were asked to sign a consent form only when they had fully understood the purpose of the study and the procedures to be undertaken for measurements of study traits. Identification information is not included in the article.

Ethical Treatment of Experimental Subjects (Animals and Humans): No experimental treatment was conducted on either human or animal subjects in this study.

Acknowledgements: The authors are thankful to Dr Baidyanath Pal of the Indian Statistical Institute in Kolkata (India) for his valuable comments during data analyses. We thank 'Itarai Asha Deep' and Dr. Ketaki Das, Public Health Research Officer, West Bengal Voluntary Health Association for organising the fieldwork. We are indebted to the Indian Statistical Institute, Kolkata (India) for logistic support.

\section{References}

1. MoS\&PI. (2011). Situation Analysis of the Elderly in India. Govt. of India. India. Retrieved July 2021, from http://mospi.nic.in/sites/default/files/publication_reports/ElderlyinIndia_2016.pdf

2. WHO. (2020). Life expectancy and Healthy life expectancy. Data by country: Global Health Observatory Data Repository. Retrieved July 2021, from https://apps.who.int/gho/data/view.main.SDG2016LEXv?lang=en

3. Fried, L. P., Tangen, C. M., Walston, J., Newman, A. B., Hirsch, C., Gottdiener, J., ... \& McBurnie, M. A. (2001). Frailty in older adults: evidence for a phenotype. The Journals of Gerontology Series A: Biological Sciences and Medical Sciences, 56(3), M146-M157. https://doi.org/10.1093/gerona/56.3.M146.

4. Biritwum, R. B., Minicuci, N., Yawson, A. E., Theou, O., Mensah, G. P., Naidoo, N., ... \& WHO Sage Collaboration. (2016). Prevalence of and factors associated with frailty and disability in older adults from China, Ghana, India, Mexico, Russia and South Africa. Maturitas, 91, 8-

18. https://doi.org/10.1016/j.maturitas.2016.05.012.

5. Mhaolain, A. M. N., Fan, C. W., Romero-Ortuno, R., Cogan, L., Cunningham, C., Kenny, R. A., \& Lawlor, B. (2012). Frailty, depression, and anxiety in later life. International Psychogeriatrics, 24(8), 1265-1274. https://doi.org/10.1017/S1041610211002110. 
6. Lohman, M., Dumenci, L., \& Mezuk, B. (2016). Depression and frailty in late life: evidence for a common vulnerability. Journals of Gerontology Series B: Psychological Sciences and Social Sciences, 71(4), 630-640. https://doi.org/10.1093/geronb/gbu180.

7. Herrera-Badilla, A., Navarrete-Reyes, A. P., Amieva, H., \& Avila-Funes, J. A. (2015). Loneliness is associated with frailty in community-dwelling elderly adults. Journal of the American Geriatrics Society, 63(3), 607-609. https://doi.org/10.1111/jgs.13308.

8. Ma, L., Zhang, L., Sun, F., Li, Y., \& Tang, Z. (2019). Cognitive function in Prefrail and frail communitydwelling older adults in China. BMC Geriatrics, 19(1), 1-7. https://doi.org/10.1186/s12877-019-10568

9. Kelaiditi, E., Cesari, M., Canevelli, M. 2., Van Kan, G. A., Ousset, P. J., Gillette-Guyonnet, S., ... \& Vellas, B. (2013). Cognitive frailty: rational and definition from an (IANA/IAGG) international consensus group. The Journal of Nutrition, Health and Aging, 17(9), 726-734. https://doi.org/10.1007/s12603013-0367-2.

10. Kashikar, Y. \& Nagarkar, A. (2016). Prevalence and Determinants of Frailty in Older Adults in India. Indian Journal of Gerontology, 30(3), 364-381.

11. Gobbens, R. J., \& van Assen, M. A. (2014). The prediction of quality of life by physical, psychological and social components of frailty in community-dwelling older people. Quality of Life Research, 23(8), 2289-2300. https://doi.org/10.1007/s11136-014-0672-1

12. Dey, S., Nambiar, D., Lakshmi, J,K, Sheikh, K \& Reddy, K.S. (2020). Health of the Elderly in India: Challenges of access and affordability, In S.I. Rajan, A. Shajan, S. Sunitha (Eds.). Ageing and Elderly Care in Kerala. China Report. (p.p. 371-86). SAGE. https://doi.org/10.1177/0009445520930393

13. Maslow, A.H. (1999). Toward a Psychology of Being. (3rd ed.). John Wiley \& Sons: New York.

14. Chaudhary, M. \& Arokiasamy, P. (2019). Patterns of Frailty and Quality of Life Among Older Adults: Comparative Analysis Using SAGE States of India. Journal of Population Ageing, 12(1), 123. https://doi.org/ 10.1007/s12062-017-9201-7.

15. MHA. (2011). Census 2011. Govt of West Bengal \& Census of India. Govt. of India. Ministry of Home Affairs. Office of the Registrar General \& Census Commissioner, India. Retrieved July 2021, from https://censusindia.gov.in/2011-common/censusdata2011.html

16. Wani, R.T. (2019). Socioeconomic Status Scales-Modified Kuppuswamy and Udai Pareekh's Scale Updated for 2019. Journal of Family Medicine and Primary Care, 8(6), 1846. https://doi.org/10.4103/jfmpc.jfmpc_288_19.

17. Mumu, S. J., Ali, L., Barnett, A., \& Merom, D. (2017). Validity of the global physical activity questionnaire (GPAQ) in Bangladesh. BMC Public Health, 17(1), 1-

10. https://doi.org/10.1186/s12889-017-4666-0.

18. Lovibond, P. F., \& Lovibond, S. H. (1995). The structure of negative emotional states: Comparison of the Depression Anxiety Stress Scales (DASS) with the Beck Depression and Anxiety Inventories. Behaviour Research and Therapy, 33(3), 335-343. https://doi.org/10.1016/0005-7967(94)00075-U 
19. Russell, D., Peplau, L. A., \& Cutrona, C. E. (1980). The revised UCLA Loneliness Scale: concurrent and discriminant validity evidence. Journal of Personality and Social Psychology, 39(3), 472. https://doi.org/10.1037/0022-3514.39.3.472.

20. Kabir, Z. N., \& Herlitz, A. (2000). The Bangla adaptation of Mini-Mental State Examination (BAMSE): an instrument to assess cognitive function in illiterate and literate individuals. International Journal of Geriatric Psychiatry, 15(5), 441-450. https://doi.org/10.1002/(SICl)10991166(200005)15:5<441::AID-GPS142>3.0.C0;2-0.

21. Feroz, A. H., Islam, M. N., ten Klooster, P. M., Hasan, M., Rasker, J. J., \& Haq, S. A. (2012). The Bengali Short Form-36 was acceptable, reliable, and valid in patients with rheumatoid arthritis. Journal of Clinical Epidemiology, 65(11), 1227-1235. https://doi.org/10.1016/j.jclinepi.2012.05.004. 